OPEN ACCESS

Edited by:

Shusheng Zhang,

Qingdao University of Science and Technology and Linyi University, China

Reviewed by:

Tania (Tali) Konry,

Harvard Medical

School-Massachusetts General

Hospital, USA

Eleonora-Mihaela Ungureanu, University Politehnica of Bucharest,

Romania

Shusheng Zhang,

Qingdao University of Science and Technology, Linyi University, China

${ }^{*}$ Correspondence:

Giacomo Ceccone giacomo.ceccone@ec.europa.eu

Specialty section:

This article was submitted to Analytical Chemistry,

a section of the journal

Frontiers in Chemistry

Received: 22 July 2015 Accepted: 05 February 2016

Published: 29 February 2016

Citation:

Spampinato V, Parracino MA, La Spina R, Rossi F and Ceccone $G$

(2016) Surface Analysis of Gold Nanoparticles Functionalized with

Thiol-Modified Glucose SAMs for Biosensor Applications.

Front. Chem. 4:8

doi: 10.3389/fchem.2016.00008

\section{Surface Analysis of Gold Nanoparticles Functionalized with Thiol-Modified Glucose SAMs for Biosensor Applications}

\author{
Valentina Spampinato ${ }^{1,2}$, Maria Antonietta Parracino ${ }^{1,3}$, Rita La Spina ${ }^{1}$, Francois Rossi ${ }^{1}$ \\ and Giacomo Ceccone ${ }^{1 *}$ \\ ${ }^{1}$ European Commission, Joint Research Centre, Institute for Health and Consumer Protection, Ispra, Italy, ${ }^{2}$ Istituto di Fisica \\ dei Plasmi, Consiglio Nazionale delle Ricerche, Milano, Italy, ${ }^{3}$ Technical Department, Nanoimmunotech S. L, Zaragoza, Spain
}

In this work, Time of Flight Secondary lon Mass Spectrometry (ToF-SIMS), Principal Component Analysis (PCA) and X-ray Photoelectron Spectroscopy (XPS) have been used to characterize the surface chemistry of gold substrates before and after functionalization with thiol-modified glucose self-assembled monolayers and subsequent biochemical specific recognition of maltose binding protein (MBP). The results indicate that the surface functionalization is achieved both on flat and nanoparticles gold substrates thus showing the potential of the developed system as biodetection platform. Moreover, the method presented here has been found to be a sound and valid approach to characterize the surface chemistry of nanoparticles functionalized with large molecules. Both techniques were proved to be very useful tools for monitoring all the functionalization steps, including the investigation of the biological behavior of the glucose-modified particles in the presence of the maltose binding protein.

Keywords: gold nanoparticles, surface functionalization, XPS, ToF-SIMS, SAMs, biodetection

\section{INTRODUCTION}

The characterization of the surface chemistry of nanomaterials to be used in complex environments such as biological media is a very challenging problem. In particular, in the case of nanoparticles to be employed in biosensing and medical applications the assessment of surface chemistry is of paramount importance to understand and tune interactions with complex biological environments (Grainger and Castner, 2008; Baer et al., 2010).

Amongst the different nanomaterials, gold nanoparticles (AuNPs) are the most attractive due to their extraordinary optical, electronic and molecular recognition properties, and for this reason they have been investigated as platform for many applications in various fields such as nanotechnology, materials science, life sciences and biosensors (Daniel and Astruc, 2004; Burda et al., 2005; Lee and El-Sayed, 2006; Njoki et al., 2007; Chen et al., 2008; Homola, 2008). The development of new strategies for synthesizing functionalized AuNPs is one of the most active research areas (Jain et al., 2007; Sperling et al., 2008). In fact, the ease by which the size and the shape of AuNPs can be modified by tuning the synthetic protocols makes them attractive for biosensing applications and nanotechnology in general (Niemeyer, 2001, 2003; Csaki et al., 2002; Katz et al., 2003; Parak et al., 2003). Moreover, it has been demonstrated that gold nanoparticles can be easily functionalized using different kind of ligands, polymers, biomolecules, etc. 
depending on the application. The strong binding affinity of AuNPs to thiols, for instance, can be exploited to assist their conjugation with biomolecules such as DNA, peptides, antibodies and proteins (Katz and Willner, 2004; Ojea-Jiménez and Puntes, 2009). Many different organosulfur compounds such as alkyl thiols and dialkyl disulphides can spontaneously form monolayers on gold substrates (self-assembled monolayers, SAMs). In fact, SAMs of alkyl thiols deposited on flat $\mathrm{Au}$ substrates have been extensively studied and characterized by several research groups in the last 30 years (Camillone et al., 1991; Dubois and Nuzzo, 1992; Biebuyck et al., 1994; Ulman, 1996; Schreiber, 2000).

In addition to flat and structured gold surfaces, thiolmodified nanoparticles can be also used as platforms for building molecular recognition systems by developing a hybrid nanomaterial bearing both the highly selective recognition properties of bimolecular antibodies and the unique electronic and photonic properties of nanoparticles. For instance, different kinds of nanoparticles have been applied as biomarkers and drugdelivery agents to tumors in the analysis and medical treatment of cancers (Brigger et al., 2002; Davis et al., 2008; Wang et al., 2012; Curry et al., 2014).

However, obtaining well-characterized and reproducible systems requires not only the quantification and the chemical identification of the different surface functionalities, but also the understanding of the influence of the different parameters involved in the surface chemical reactions (Grainger and Castner, 2008; Baer et al., 2010; Ambrogio et al., 2013; Neoh et al., 2015). In this respect, surface analysis spectroscopic methods such as X-ray Photoelectron Spectroscopy (XPS) and Time of Flight Secondary Ion Mass Spectrometry (ToF-SIMS) are increasingly being used to investigate the surface composition of nanomaterials ranging from metallic, oxides, semiconductors and carbon-based (Zhang et al., 2004; Okpalugo et al., 2005; Yang et al., 2005; Pinnick et al., 2008; Zorn et al., 2011; Shard, 2012; Spampinato et al., 2015). Moreover, XPS and ToF-SIMS have been used to study the interaction of biomolecules with surfaces including nanofilms and nanoparticles (Ray and Shard, 2011; Techane et al., 2011; Lebec et al., 2013; Park and Shumaker-Parry, 2014; Kim et al., 2015).

In this work, citrate stabilized AuNPs have been functionalized with a thiol-modified glucose to study the interaction with a periplasmic binding protein (Oliver et al., 2009), the maltose binding protein (MBP); this protein has a molecular weight of $48 \mathrm{kDa}$ and bears the binding site in the cleft between the protein domains (Maina et al., 1988; Xavier et al., 1996; Kapust and Waugh, 1999). Thanks to its specificity and high solubility in aqueous solvents, this protein can be used as recognition element in biosensors for small analytes such as glucose (De Champdore et al., 2006; Medintz and Deschamps, 2006), for instance in monitoring sugar level in blood of patients with diabetes disease (Fonin et al., 2014).

In our study, ToF-SIMS allowed the identification of some characteristic peaks related to the coordination of thio-glucose with gold substrates as well as with the binding pocket of the protein, whilst XPS provided quantitative information about the elements content in each functionalization step. Moreover, from the XPS high-resolution spectra information about the bonds formed between the different species involved in the functionalization were also inferred.

\section{MATERIALS AND METHODS}

\section{Sample Preparation: Au NPs Synthesis and Functionalization}

Synthesis of $15 \mathrm{~nm}$ sized Au NPs was carried out by modification of the procedure described by Turkevich et al. (1951), in which the gold nanoparticles were produced by the reduction of the gold salt by the sodium citrate that acts as reducing agent and stabilizer. The solution was heated up using a specialized microwave apparatus (Discover S by CEM corporation), which ensured high reproducibility, rapid and uniform heating process. In this method, $5 \mathrm{ml}$ of tetrachloroauric acid trihydrate 0.01 $\mathrm{M}\left(\mathrm{HAuCl}_{4} \cdot 3 \mathrm{H}_{2} \mathrm{O}\right)$ (CAS No: 16961-25-4, Sigma-Aldrich, Italy) were dissolved in $95 \mathrm{ml}$ of water. The solution was rapidly heated up to $97^{\circ} \mathrm{C}$ and held for 5 min using a maximum microwave power of $250 \mathrm{~W}$ under vigorous mechanical stirring. In such condition, $2.5 \mathrm{ml}$ of trisodium citrate dihydrate $0.1 \mathrm{M}$ (SigmaAldrich) were added to the solution and kept at $97^{\circ} \mathrm{C}$ for further $20 \mathrm{~min}$. Afterwards, the solution vessel was rapidly cooled down to $40^{\circ} \mathrm{C}$ by a flow of compressed nitrogen.

Pristine AuNPs were used as substrates for functionalization. First, the nanoparticles were mixed overnight with a solution of 1-ß-D-thio-glucose $(0.5 \mathrm{mM}, 5 \mathrm{n}$ water ethanol 1:1), henceforth referred as TG, (CAS No: 10593-29-0, $\mathrm{Mw}=\mathrm{C}_{6} \mathrm{H}_{11} \mathrm{O}_{5} \mathrm{SNa}$ Sigma Aldrich, Italy) so that a self-assembled monolayer could be formed on the gold surface via the S-Au bond. Then, in order to remove the excess of TG, a dialysis procedure against milliQ water was performed. The dialysis was carried out by means of cellulose membrane tubes (cut off 10000 Da, Sigma Aldrich, Italy). Before use, the dialysis tubes were washed with milliQ water and then left in boiling water for few minutes in stirring conditions. The water was poured out and the step repeated with clean water. The residual water inside the tube was removed and one end was folded and sealed with a plastic clip. $5 \mathrm{ml}$ of AuNPs were then poured into the tube and the other end of the tube was also folded and clipped before being immersed in a beaker containing $250 \mathrm{ml}$ of milliQ water. The sample was then allowed to dialyse for $1 \mathrm{~h}$ before replacing the water. The sample was subjected to total of six cycles of dialysis at which point the purified solution was analyzed and found to contain a $0.2 \mathrm{mM}$ concentration of gold nanoparticles.

The TG-functionalized AuNPs were used as platform for studying the biological recognition with a protein, the maltose binding protein, henceforth MBP (AbCam, United Kingdom), which is a periplasmic binding protein involved in the transport of maltodextrins. The TG-functionalized AuNPs were mixed overnight with a MBP solution (10 $\mathrm{mM}$ buffer phosphate, $\mathrm{pH}$ ), allowing the interaction between the sugar anchored onto the surface and the protein. In order to remove the excess of protein the solution was centrifuged at $4^{\circ} \mathrm{C}$ and $10000 \mathrm{rpm}$ for 15 min after which the majority of the supernatant solution was discarded and replaced with ultrapure water. The particles were 
then re-suspended by shaking before repeating the centrifugal purification step. This was repeated three times after which the suspension was then stored in the fridge at $4^{\circ} \mathrm{C}$ until further analysis was conducted.

\section{Sample Preparation: Au Flat Substrate}

For comparison with the nanoparticles, a bare gold film of about $50 \mathrm{~nm}$ in thickness, prepared by means of a magnetron sputtering reactor (Leybold, Germany), was used as substrate for the functionalization. First, the substrate was treated with $\mathrm{UV}-\mathrm{O}_{3}$ for $30 \mathrm{~min}$ in order to remove possible organic contaminants on the surface, rinsed with water and ethanol and dried under a flow of high purity $\mathrm{N}_{2}$. The cleaned substrate was immersed overnight in a 1-B-D-thio-glucose (TG) solution $(0.5 \mathrm{mM}$, water/ethanol 1:1) to form a self-assembled monolayer of TG on the gold surface. The sample was subsequently rinsed with water and ethanol in order to remove the TG in excess and then dried under $\mathrm{N}_{2}$ flow. The TG-modified substrate was used as platform for biological recognition experiments with the maltose binding protein (MBP). For this, the sample was dipped overnight in a MBP solution (10 mM buffer phosphate, $\mathrm{pH} 7$ ), then rinsed first with PBS buffer, then with water and dried under $\mathrm{N}_{2}$ flow.

\section{Sample Characterization}

In order to assess the size distributions of the nanoparticles, Centrifugal Liquid Sedimentation (CLS) measurements were performed on the as-synthesized nanoparticle dispersions (DC24000UHR, CPS Instruments). Measurements were carried out using an $8 \mathrm{wt} \%-24 \mathrm{wt} \%$ sucrose density gradient with a disc speed of $22000 \mathrm{rpm}$. Each sample injection of $1 \mu \mathrm{l}$ was preceded by a calibration step performed using certified PVC particle size standards with weight means size of $380 \mathrm{~nm}$. Further characterization of the AuNPs size and morphology was performed by Scanning Electron Microscope (FEI NOVA 600I, Nanolab). The particle size distribution was also determined by dynamic light scattering (DLS, Malvern Zetasizer Nano-ZS).

ToF-SIMS analysis was conducted using a reflection-type TOFSIMS-IV spectrometer (ION-TOF GmbH, Münster, Germany) equipped with a $25 \mathrm{keV}$ liquid metal ion gun (LMIG) operating with bismuth primary ions. Spectra were acquired in static mode (primary ion fluence $<10^{12}$ ions $\cdot \mathrm{cm}^{-2}$ ) in order to preserve the molecular information. During analysis, charging of the surface was prevented by applying charge compensation using low-energy $(\sim 20 \mathrm{eV})$ electron flood gun. Mass calibration of ToF-SIMS spectra was performed by using the hydrocarbon peaks $\mathrm{CH}^{+}(13 \mathrm{u}), \mathrm{CH}_{3}^{+}(15 \mathrm{u}), \mathrm{C}_{2} \mathrm{H}_{3}^{+}(27 \mathrm{u})$, $\mathrm{C}_{3} \mathrm{H}_{5}^{+}(41 \mathrm{u}), \mathrm{C}_{5} \mathrm{H}_{7}^{+}(67 \mathrm{u})$, and $\mathrm{C}_{7} \mathrm{H}_{7}^{+}(91 \mathrm{u})$ for positive ions spectra. Analyses were obtained from square areas of $250 \times$ $250 \mu \mathrm{m}$ in high mass resolution burst mode (resolution $\mathrm{M} / \Delta \mathrm{M}$ $>6000$ ). Spectral interpretation was carried out using Surface Lab software v6.4 (ION-TOF GmbH, Münster, Germany). Principal Component Analysis (PCA) was performed using the NESAC/BIO MVA Toolbox (Spectragui v2.7 standalone, https://www.nb.engr.washington.edu/mvsa/nbtoolbox). Scores were plotted with the $95 \%$ confidence limit. Prior to PCA analysis, a data pre-processing step was applied to the dataset to remove variance that is not due to chemical differences between the samples. In particular, the mass spectra were first normalized to the sum of selected peaks, to account for fluctuations in secondary ion yield between different spectra and then SQRT-mean-centered.

XPS measurements were carried out with an Axis Ultra spectrometer (Kratos Analytical, Manchester, UK), using a K $\alpha$ $\mathrm{Al}$ monochromatic source $(\mathrm{h} v=1486.6 \mathrm{eV})$ operating at $150 \mathrm{~W}$ and X-ray spot size of $400 \times 700 \mu \mathrm{m}^{2}$ in hybrid mode. The residual pressure of the analysis chamber during the analysis was less than $8 \times 10^{-9}$ Torr. For each sample, at least three survey spectra $(0-1150 \mathrm{eV}$ at pass energy of $160 \mathrm{eV})$ were acquired and used to determine the surface chemical composition (at\%). In addition, one set of high-resolution spectra (analyzer pass energy at $20 \mathrm{eV}$ ) was recorded to obtain information about the chemical bonding of the different elements. Surface charge was compensated by a magnetic charge compensation system and the energy scale calibrated by setting the $\mathrm{C} 1$ s hydrocarbon peak to $285 \mathrm{eV}$. The take-off angle for the acquisitions was $90^{\circ}$ with respect to the sample surface. The acquisition time was kept below 20 min per sample to avoid possible X-ray damage and wide and core level spectra were acquired on different sample positions. The data were processed using Vision2 software (Kratos Analytical, UK) and the analysis of the XPS peaks was performed using a commercial software package (Casa XPS v2.3.16PR1, Casa Software Ltd., UK). The atomic percentages (at\%) were calculated from the experimentally determined peak intensities and normalized by atomic sensitivity factors provided by Kratos Analytical. Peak fitting was performed with no preliminary smoothing. Symmetric Gaussian-Lorentzian (70\% Gaussian and 30\% Lorentzian) product functions were used to approximate the line shapes of the fitting components after a Shirley-type background subtraction.

\section{RESULTS AND DISCUSSION}

The main goal of this work was to characterize and assess the surface chemistry of the different functionalization steps of $\mathrm{Au}$ nanoparticles with 1-B-D-thio-glucose (TG) and the interaction with maltose binding protein (MBP). However, in order to discuss the data related to the AuNPs, we consider it useful to first present the results related to the functionalization of gold films as this will help in addressing some important issues related to the functionalized Au particles.

\section{Functionalization of Gold Flat Substrates}

XPS and ToF-SIMS measurements were performed after each functionalization step in order to obtain information about the functionalization and the chemistry of the modified surface. In Table 1 the surface compositions obtained from the XPS data are reported, whilst in Figure $\mathbf{1}$ the C1s and the S2p core level spectra recorded on the Au flat substrate, before and after the reaction with the thio-glucose, are shown.

After the TG functionalization, an increase in oxygen and carbon content, due to the TG molecule, was detected, while a decrease of gold content was observed because of the presence of the self-assembled monolayer onto the surface. Moreover, after the reaction with TG, the appearance of sulfur (about 2.6 
TABLE 1 | Surface compositions of the different Au flat samples obtained from XPS analysis.

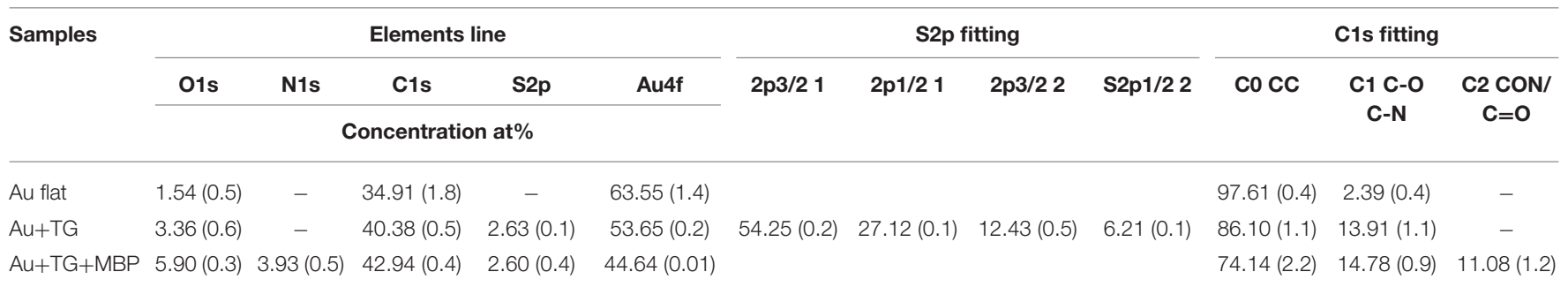

(Standard Deviation in brackets).
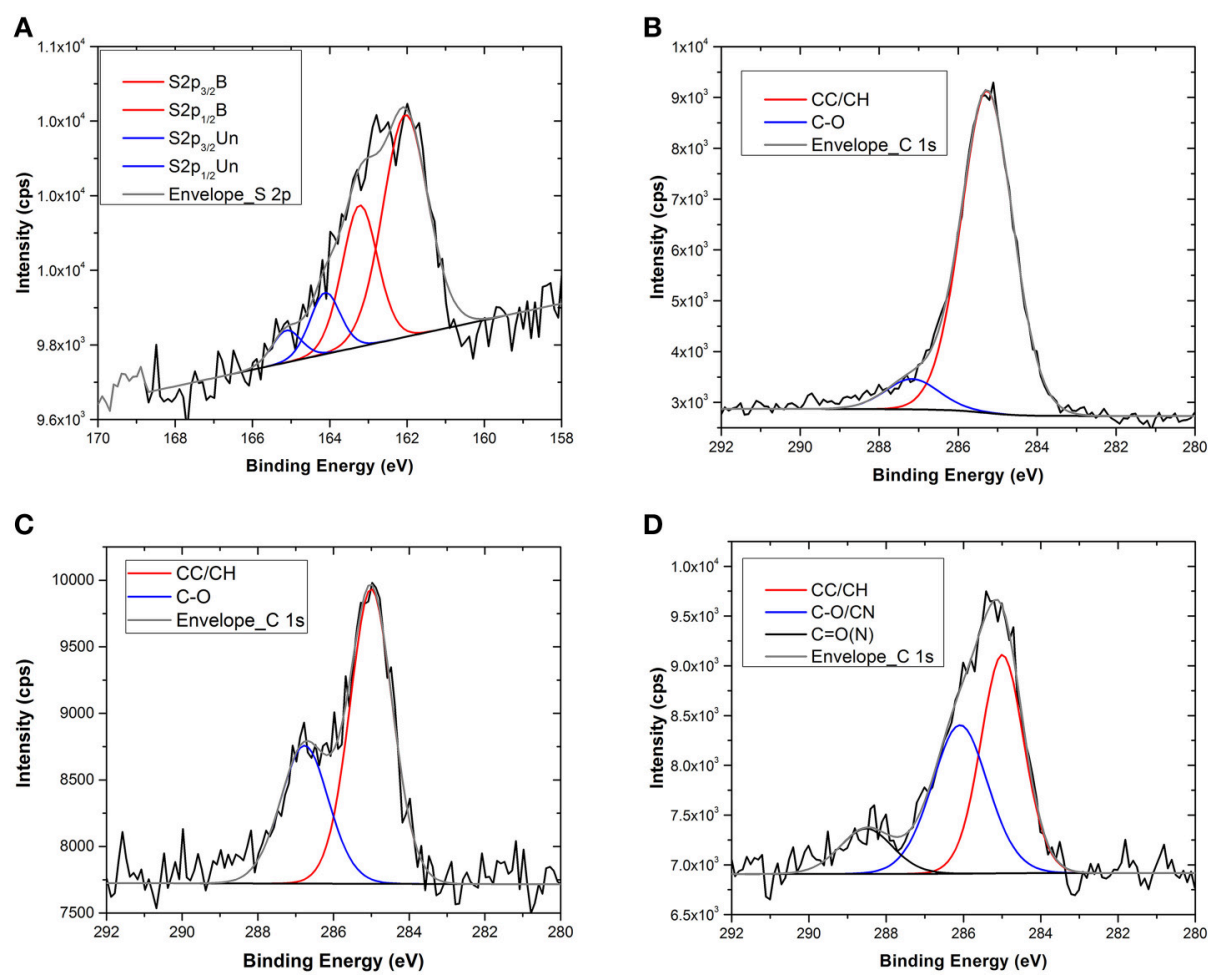

FIGURE 1 | S2p and C1s core level spectra of the flat gold substrate before and after TG functionalization (A-C) and after interaction with MBP (D).

at\%) was also observed, whilst the carbon and oxygen content increases. All these results indicate the presence of TG at the Au surface.

Additional information was obtained from the analysis of the $\mathrm{C} 1 \mathrm{~s}$ and S2p core level spectra (Figure 1). In particular, looking at the high-resolution XPS spectrum of S2p (Figure 1A) it is possible to conclude that the functionalization occurred via S$\mathrm{Au}$ chemical bond because of the presence of the component at $162 \mathrm{eV}$. In fact, the S2p peak can be fitted with two components, each one accounting for the spin-orbit splitting doublet $\mathrm{S} 2 \mathrm{p}_{1 / 2}$ and $\mathrm{S} 2 \mathrm{p}_{3 / 2}(\Delta \mathrm{E} \cong 1.2 \mathrm{eV})$. The first component, centered at about $162 \mathrm{eV}$, is assigned to the bound sulfur; the second one (at about $164 \mathrm{eV}$ ) is related to the presence of some unbound sulfur on the surface. While the first component is related to the chemisorption of thiols, the second one underlines a certain degree of weakly bound (physisorbed) thiols that remain on the surface even if the samples were carefully rinsed with ethanol and water. The presence of this component is known in literature ( $\mathrm{Lu}$ et al., 2000; Vericat et al., 2006) and could be due to the high density of TG molecules that form the self-assembled monolayer onto the surface. Generally, for this kind of SAM, a lateral spacer that could assist the self-assembled monolayer formation by reducing the number of molecules reacting with the substrate should be used (Cyganik et al., 2004). Indeed, since TG is a very small molecule that forms a film with thickness of less than $1 \mathrm{~nm}$, the use of a spacer could provide higher flexibility and stability to the system. However, since the purpose of this study was to perform surface analysis, it was decided to reduce the system complexity by limiting as far as possible the number of functionalization steps. In any case, from the S2p fitting, it results that the percentage of S2p bound to the surface was definitely higher that the unbound one (about 80 vs. 20\%) indicating the 

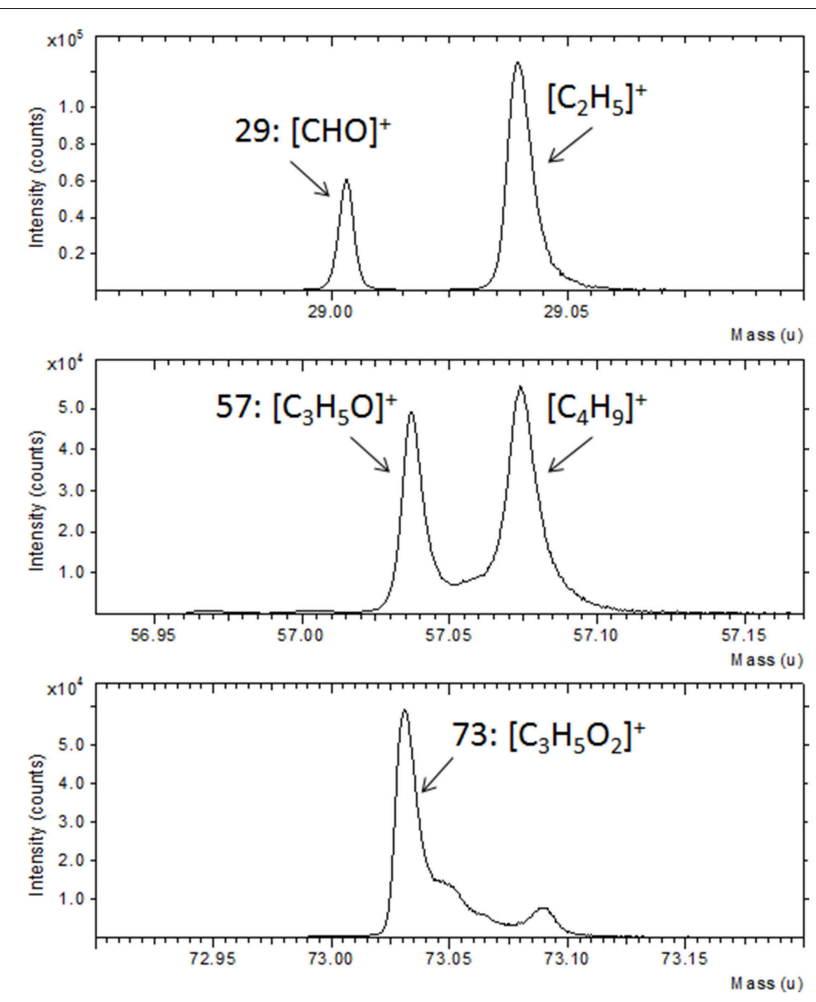

FIGURE 2 | Portion of ToF-SIMS positive spectra of Au film after reaction with TG thiols.

successful occurrence of the functionalization. Moreover, analysis of the $\mathrm{C} 1 \mathrm{~s}$ core level spectra before and after the reaction with the TG thiols revealed an approximately six-fold increase of the component related to the $\mathrm{C}-\mathrm{O}$ bonds $(286.5 \mathrm{eV})$ attributable to the presence of the TG thiols (Figures 1B,C, Table 1).

Further confirmation of the TG functionalization was obtained by the ToF-SIMS analysis. In Figure 2 a portion of the ToF-SIMS positive spectrum of the TG-modified Au substrate is shown (the entire spectrum is reported in Figure SI). Some characteristic peaks, containing $\mathrm{C}, \mathrm{H}$, and $\mathrm{O}$, coming from the fragmentation of the sugar, are shown. In particular, it is possible to identify the fragments $[\mathrm{CHO}]^{+}$at $29 \mathrm{u},\left[\mathrm{CH}_{3} \mathrm{O}\right]^{+}$at $31 \mathrm{u},\left[\mathrm{C}_{2} \mathrm{H}_{5} \mathrm{O}\right]^{+}$at $45 \mathrm{u},\left[\mathrm{CH}_{3} \mathrm{O}_{2}\right]^{+}$at $47 \mathrm{u},\left[\mathrm{CH}_{5} \mathrm{O}_{2}\right]^{+}$at $49 \mathrm{u}$, $\left[\mathrm{C}_{3} \mathrm{H}_{5} \mathrm{O}\right]^{+}$at $57 \mathrm{u},\left[\mathrm{C}_{2} \mathrm{H}_{4} \mathrm{O}_{2}\right]^{+}$at $60 \mathrm{u},\left[\mathrm{C}_{2} \mathrm{H}_{5} \mathrm{O}_{2}\right]^{+}$at $61 \mathrm{u}$, and $\left[\mathrm{C}_{3} \mathrm{H}_{5} \mathrm{O}_{2}\right]^{+}$at $73 \mathrm{u}$. These mass peaks were not detected during the analysis of the gold substrate suggesting the success of the TG functionalization process.

After the reaction with the MBP the surface composition change drastically as shown in Table 1 . The presence of nitrogen and the increase of carbon and oxygen together with the decrease of gold signal indicate the presence of the protein on the $\mathrm{Au}$ surface. Moreover, the persistence of S2p signal indicates that the interaction with the MBP occurred through the TG thiol SAMs. Further, evidence of the interaction with the MBP was found in the analysis of the C1s high-resolution XPS spectra (Figure 1D). The C1s peak can be fitted with three components: $\mathrm{C} 0$ at about $285 \mathrm{eV}$ related to the $\mathrm{C}-\mathrm{C} / \mathrm{C}-\mathrm{H}$ hydrocarbon bonds, $\mathrm{C} 1$ at about $286.5 \mathrm{eV}$ ascribed to the C$\mathrm{O}$ and $\mathrm{C}-\mathrm{N}$ bonds, and $\mathrm{C} 2$ at about $288.5 \mathrm{eV}$ relative to the $\mathrm{C}=\mathrm{O}$ and $\mathrm{C}-\mathrm{N}-\mathrm{O}$ bonds. The bare gold substrate shows the presence of the first two components and this can be explained considering the small amount of oxygen (less than 2\%) detected already on the bare substrate. However, the $\mathrm{C} 1$ component increases (from 2 to $14 \%$ ) when the functionalization with the TG occurs, because of the oxygen atoms present in the TG molecules. The third component $\mathrm{C} 2$ is visible only for the sample functionalized with the MBP and can be related to the peptide bond involved in the protein structure (Vanea and Simon, 2011).

ToF-SIMS data support the XPS result as illustrated in Figure 3, where a portion of positive spectrum in the mass range between 1 and $200 \mathrm{u}$ is shown. This portion of the spectrum was analyzed for the interaction of the Au-TG surface with the MBP, since it is well known from the literature (Wagner and Castner, 2001) that protein fragmentation leads to the formation of molecular fragments related to the constituent amino acids of the protein. For example peaks at $60 \mathrm{u}$ can be ascribed to serine, the ones at 68 and $70 \mathrm{u}$ to proline, peaks at 69 and $74 \mathrm{u}$ to threonine, peaks at 73 and $100 \mathrm{u}$ can be related to arginine, peak at $82 \mathrm{u}$ to lysine, peak at $88 \mathrm{u}$ either to asparagine or aspartic acid and peak at $130 \mathrm{u}$ to tryptophan (Wang et al., 2004).

Overall our results on the Au film indicate that the functionalization with TG thiols can be performed with a relatively simple process and that the interaction with MBP does not influence the Au-S bonding between the TG and the $\mathrm{Au}$ surface. These findings are a good starting point to explore the possibility of applying a similar process to gold nanoparticles.

\section{Functionalization of Gold Nanoparticles}

The size and morphology of synthesized nanoparticles was characterized by means of DLS, CPS, and SEM. The results are presented in Table 2, whilst a typical CLS determined particle size distribution and SEM images are reported in Figure SI1.

To perform the surface analysis measurements, $100 \mu \mathrm{l}$ of suspension were spotted on titanium films (about $70 \mathrm{~nm}$ in thickness deposited by means of a magnetron sputtering reactor) and dried under a fume hood for $1-2 \mathrm{~h}$, then inserted in the loadlock chamber ( $\mathrm{p} \sim 5 \times 10^{-7}$ Torr) where they were degassed overnight before ToF-SIMS and XPS analysis.

In Table 3 the atomic compositions of the Au nanoparticles, obtained from the XPS wide spectra, before and after the surface functionalization and interaction with MBP, (see also Figure SI2) are presented.

As can be read from the table, the titanium substrate contains around 57 and $21 \%$ of oxygen and carbon respectively, which makes the discussion about the functionalization process based on these two elements difficult and ambiguous. Moreover, the pristine $\mathrm{Au}$ NPs show quite high amount of $\mathrm{Na}, \mathrm{C}$, and $\mathrm{O}$ that strongly mask the Au signal. This can be attributed to a quite thick layer of citrate present on the nanoparticles. Looking at the gold and sodium (as counter ion for the citrate stabilizer) percentage before and after the reaction with the TG, it is quite clear that a displacement of the citrate stabilizer by the sugar is occurring. In fact, a decrease of Na1s from 22 to 12 

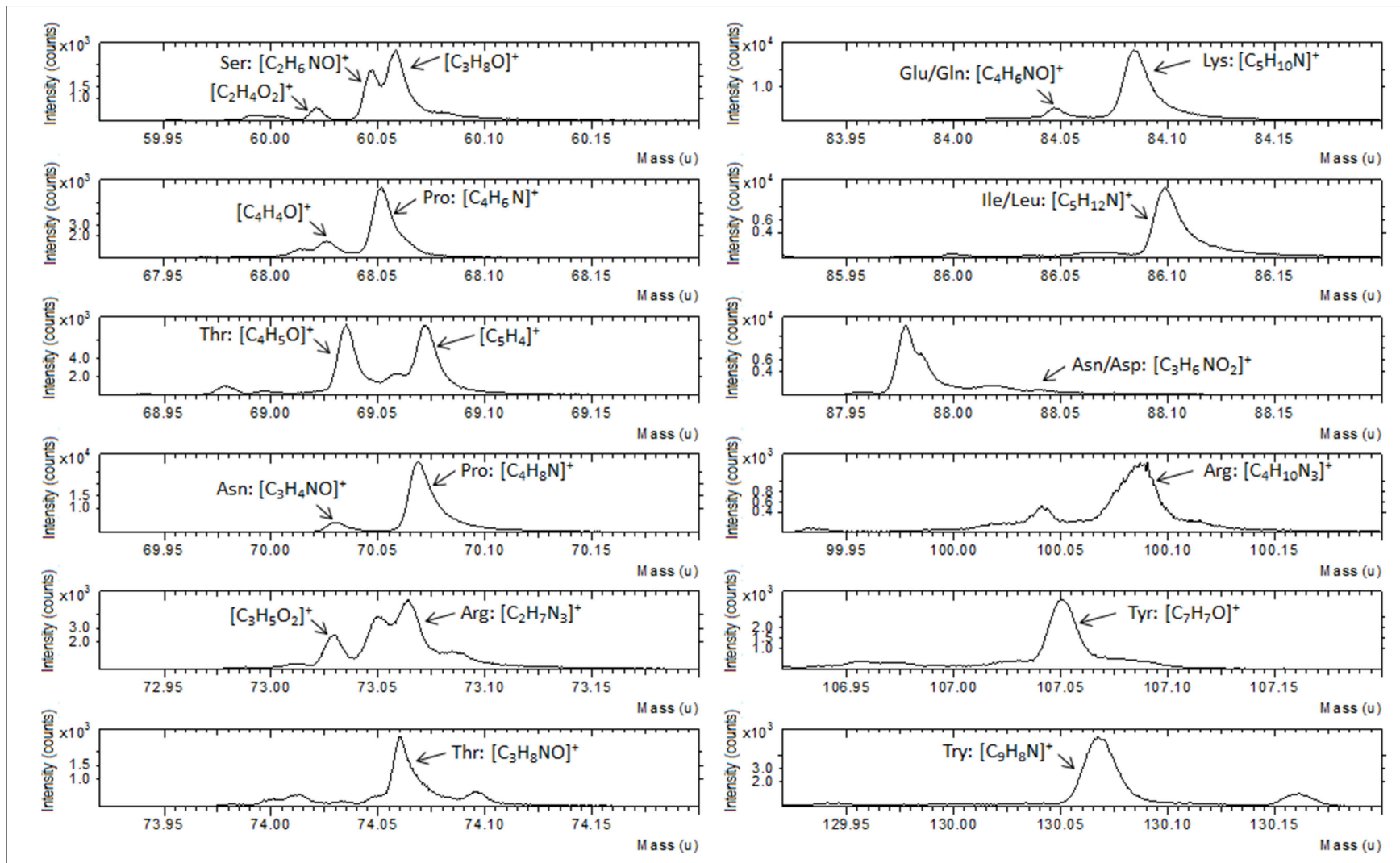

FIGURE 3 | Portion of ToF-SIMS positive recorded on Au film functionalized with TG thiols and after reaction with the MBP.

at $\%$ and a correspondent increase of Au4f from 2 to 6 at\%, indicates a partial removal of the thick citrate layer during the functionalization process and the subsequent dialysis washing procedure. A small amount of chlorine (less than 3\%) was detected on the pristine AuNPs, which is probably a residue of the $\mathrm{HAuCl}_{4}$ precursor used in the particles synthesis. However, after reaction with the TG the $\mathrm{Cl} 2 \mathrm{p}$ is reduced to less than 1 at $\%$, suggesting that this element is largely displaced during the reaction with TG thiols. As already observed in the case of the flat substrate, after the reaction with TG the appearance of S2p signal is detected at the nanoparticles surface. However, the amount of sulfur is much lower than in the case of the flat substrate indicating a lower degree of TG functionalization of the AuNPs. Despite this low sulfur amount, analysis of the S2p core level spectrum (Figure 4) provides a sound proof that TG is mostly chemisorbed onto the Au NPs surfaces. In fact, the S2p peak can be again fitted with two components (each one composed of a spin-orbit splitting doublet) as already described for the flat substrate: the first component, centered at about $162 \mathrm{eV}$, related to the bound TG thiols, whilst the second component due to the weakly bound thiols, indicating that despite the dialysis cleaning process about $30 \%$ of unbound TG thiols is still present on the Au nanoparticles surface. The fact that the $\mathrm{Au}$ NPs show a lower degree of functionalization could be expected because of the presence of the citrate that needs to be displaced by the TG thiols. In fact, in some recent studies Park
TABLE 2 | Size characterization of pristine gold nanoparticles: $d_{C L S}(\mathrm{~nm})$ represents the average size of the AuNPs calculated by CLS, $\sigma_{D L S}(\mathrm{~nm})$ is the size distribution by CLS calculated at Half Height Width (HHW) of the AuNPs peak.

\begin{tabular}{|c|c|c|c|c|c|}
\hline & $\begin{array}{c}d_{C L S} \pm \sigma_{C L S} \\
(\mathrm{~nm})\end{array}$ & $\begin{array}{c}\mathrm{DI}_{C L S} \\
(\mathrm{~nm})\end{array}$ & $\begin{array}{c}d_{D L S} \pm \sigma_{D L S} \\
(\mathrm{~nm})\end{array}$ & $\begin{array}{c}P D I_{D L S} \\
(\mathrm{~nm})\end{array}$ & $\begin{array}{c}D_{S E M} \pm \sigma_{S E M} \\
(\mathrm{~nm})\end{array}$ \\
\hline $15 \mathrm{~nm}$ AuNPs & $11.0 \pm 1.4$ & 1.05 & $14.0 \pm 0.2$ & 0.03 & $14 \pm 2$ \\
\hline
\end{tabular}

$D_{C L S}(n m)$ is the CLS Polydispersity Index expressed as the ratio $D_{w} / D_{n}$ (where the $D_{w}$ is the average particle size calculated from the particle weight-size distribution while $D_{n}$ is the average particle size calculated from the equivalent number-size distribution); $d_{D L S}$ $(n m)$ is the average size calculated by $D L S$; $S_{D L S}$ is the standard deviation between several measurement; $P D I_{D L S}$ is the dimensionless polydispersity index; $d_{S E M}(n m)$ and $s_{S E M}$ are respectively are the average size of the AuNPS calculated by SEM, and the analysis is performed by ImageJ software.

and Shumaker-Parry have shown that the citrate is not readily displaced by thiols suggesting that a less dense functionalization occurs on citrate stabilized nanoparticles with respect to flat substrates ToF-SIMSn analysis support the XPS data as illustrated in Figure 5 where a portion of the positive ToF-SIMS spectrum of the TG modified AuNPs is reported. As can be seen the same peaks related to the TG fragmentation already observed for the flat substrate (Figure 3) are detected (Park and Shumaker-Parry, 2014, 2015).

After interaction with MBP, the composition of the Au NPs surfaces changes quite drastically (Table 3 ). In particular, a 
TABLE 3 | Surface compositions of Au nanoparticles before and after functionalization with TG and interaction with MBP.

\begin{tabular}{|c|c|c|c|c|c|c|c|c|c|c|c|c|}
\hline \multirow[t]{2}{*}{ Samples } & \multicolumn{8}{|c|}{ Elements line } & \multicolumn{4}{|c|}{ S2p fitting } \\
\hline & \multicolumn{8}{|c|}{ Concentration at $\%$} & & & & \\
\hline Ti substrate & - & $56.93(0.3)$ & - & $22.31(0.1)$ & $20.77(0.3)$ & - & - & - & & & & \\
\hline AuNPs pristine & $21.83(0.5)$ & $36.06(0.7)$ & - & $2.89(0.6)$ & $34.93(0.6)$ & $2.74(0.4)$ & - & $1.55(0.2)$ & & & & \\
\hline AuNPs+TG & $11.56(1.9)$ & $34.99(1.7)$ & - & $4.86(1.0)$ & $41.49(1.5)$ & $0.31(0.03)$ & $0.49(0.2)$ & $6.30(1.3)$ & $47.40(0.2)$ & $23.69(0.1)$ & $19.28(0.2)$ & $9.64(0.1)$ \\
\hline
\end{tabular}

(Standard Deviation in brackets).

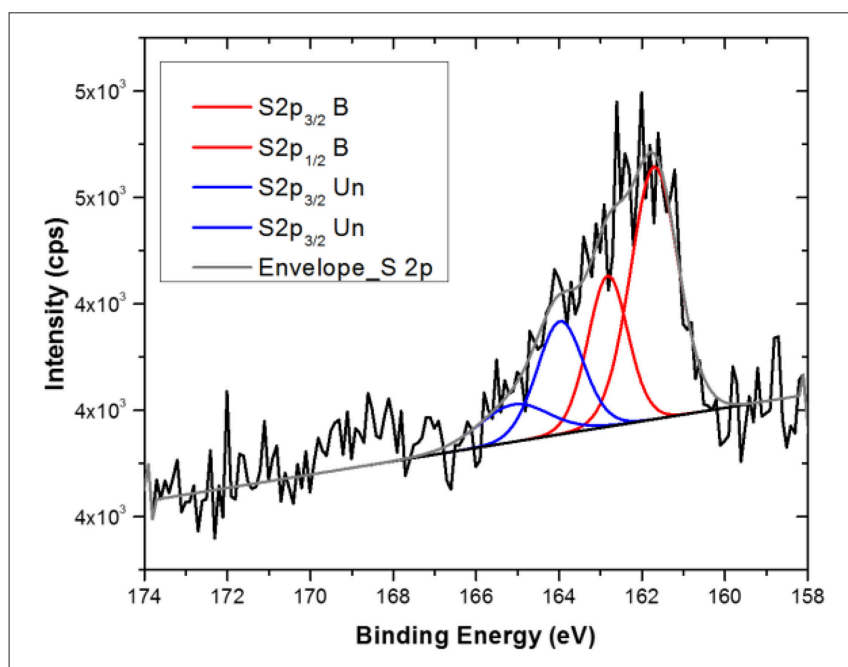

FIGURE 4 | S2p XPS Core level spectra of Au NPs after functionalization with TG thiols.

nitrogen content (up to 7 at\%), almost double than for flat Au substrate, (Table 2) is detected. Moreover, the decrease of the Au signal and the increase of the carbon content are also observed. These data prove the presence of the MBP on the surface of the nanoparticles. In addition, the Na1s signal disappears, whilst the oxygen signal decreases, indicating a possible displacement of the remaining citrate during the interaction with the protein and the subsequent washing procedure. Since, in comparison with the case of the flat $\mathrm{Au}$ film the $\mathrm{Au} \mathrm{NPs} \mathrm{appear} \mathrm{to} \mathrm{have}$ a lower TG functionalization density, it is likely that part of the protein is interacting directly with the surface of the nanoparticles.

Additional evidence of the presence of the MBP was found in the analysis of the C1s high-resolution XPS spectra (Figure SI3), even if the presence of the citrate makes the interpretation of the spectra less straightforward. As in the case of Au flat substrate, after the reaction with the TG thiols, an increase of the component related to the $\mathrm{C}-\mathrm{O}$ moieties $(286.5 \mathrm{eV})$ of the thioglucose is observed, whilst the increase of the component attributable to $\mathrm{CO}(\mathrm{N})$ bonds $(\sim 288.5 \mathrm{eV})$ is detectable after the interaction with MBP.

Analysis by ToF-SIMS provided strong support to the XPS data also in the case of Au NPs. In particular, following the

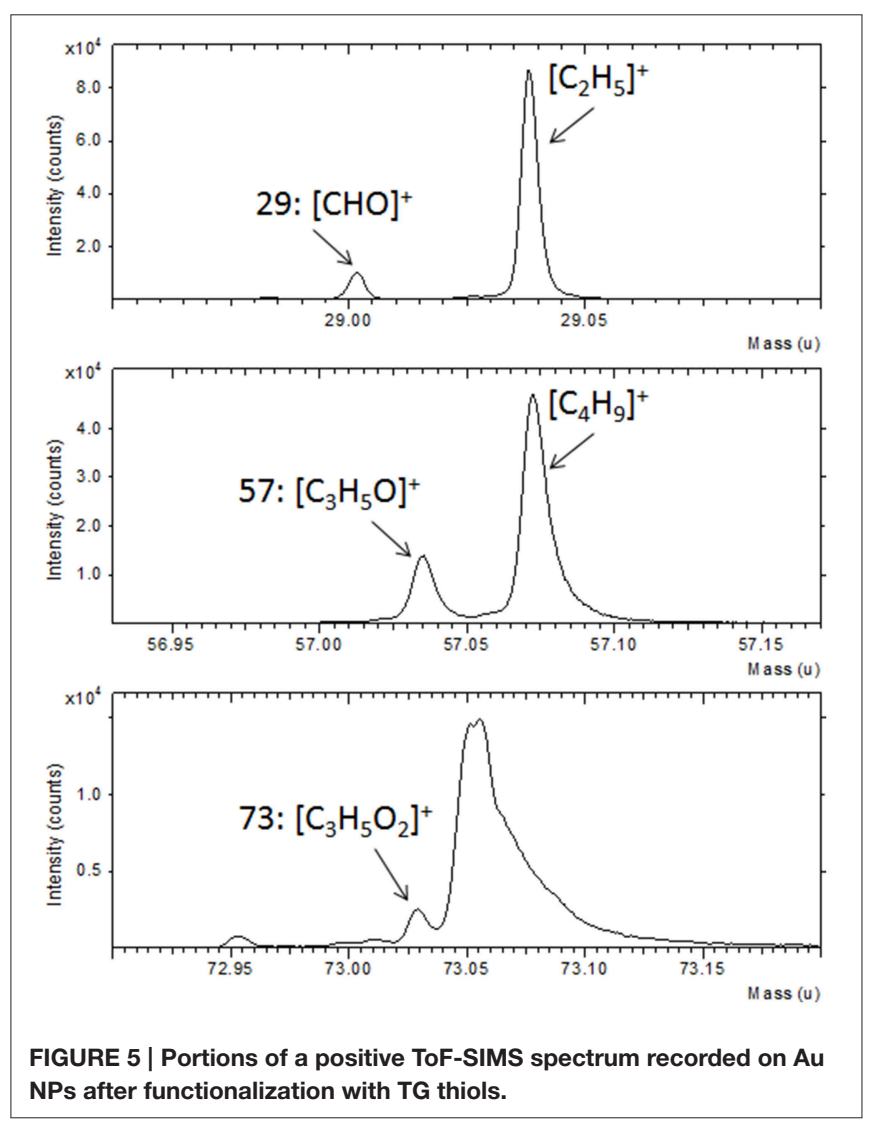

results shown above, we have concentrated our attention on the fragments related to the different amino acids in the mass range between 1 and $200 \mathrm{u}$ (Figure 6A). A similar fragmentation pattern, including peaks attributable to the same amino acids already detected in the case of the flat $\mathrm{Au}$ film is observed (Figure 3). Moreover, the analysis of the entire spectrum, reported in Figure 6B reveals also some fragments in the mass range between 300 and $800 \mathrm{u}$. These peaks can be attributed to the TG molecule interacting with one aspartic acid and one arginine residue. In particular, the peak at $358 \mathrm{u}$ corresponding to the fragment $\mathrm{C}_{11} \mathrm{H}_{26} \mathrm{~N}_{4} \mathrm{O}_{7} \mathrm{~S}$ can be ascribed to the TG molecule interacting with one aspartic acid and one arginine residue, while the same fragment bearing additional oxygen and cationized with gold is be detected at 375 and $555 \mathrm{u}$, respectively. Furthermore, at 
A
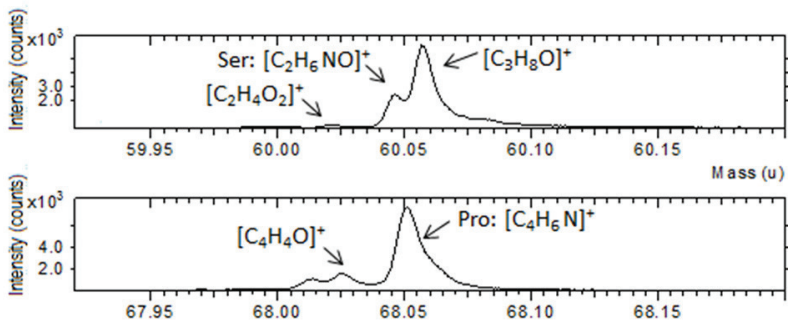

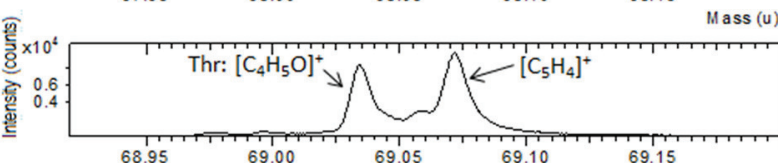
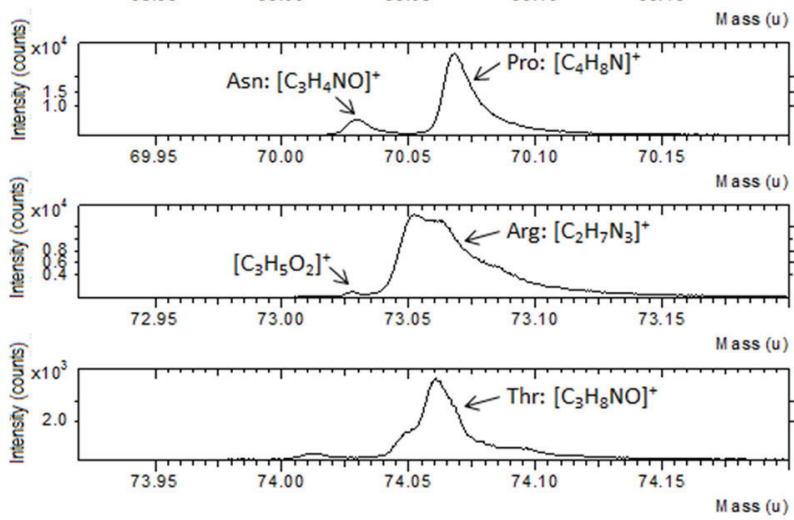
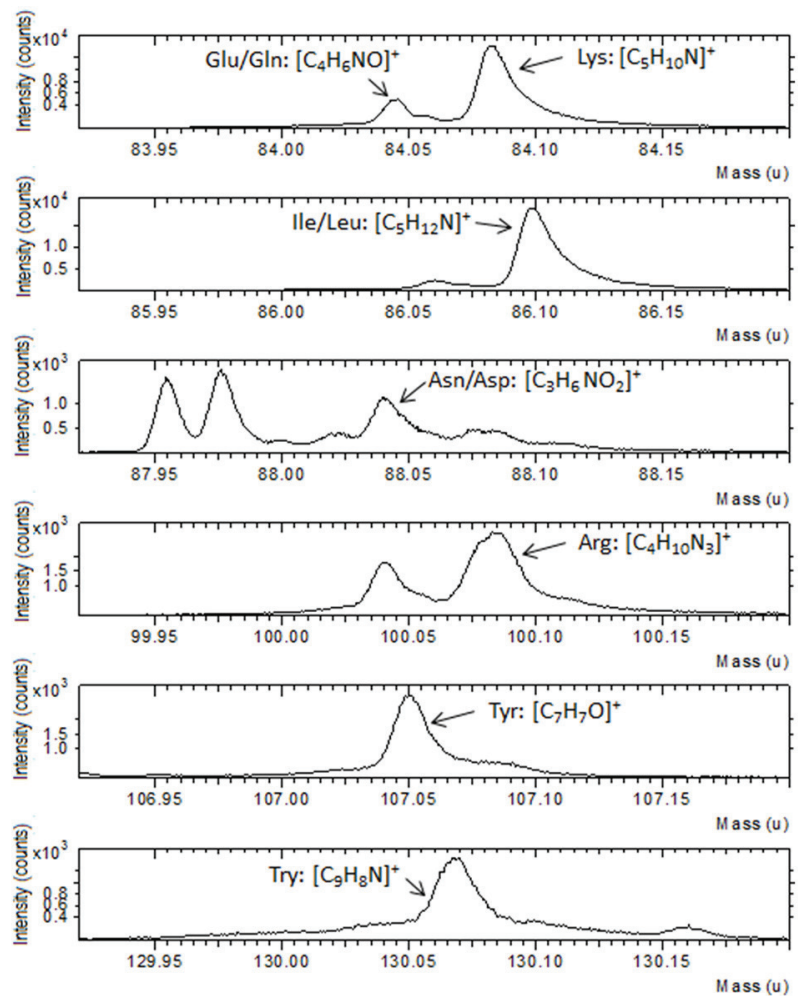

B
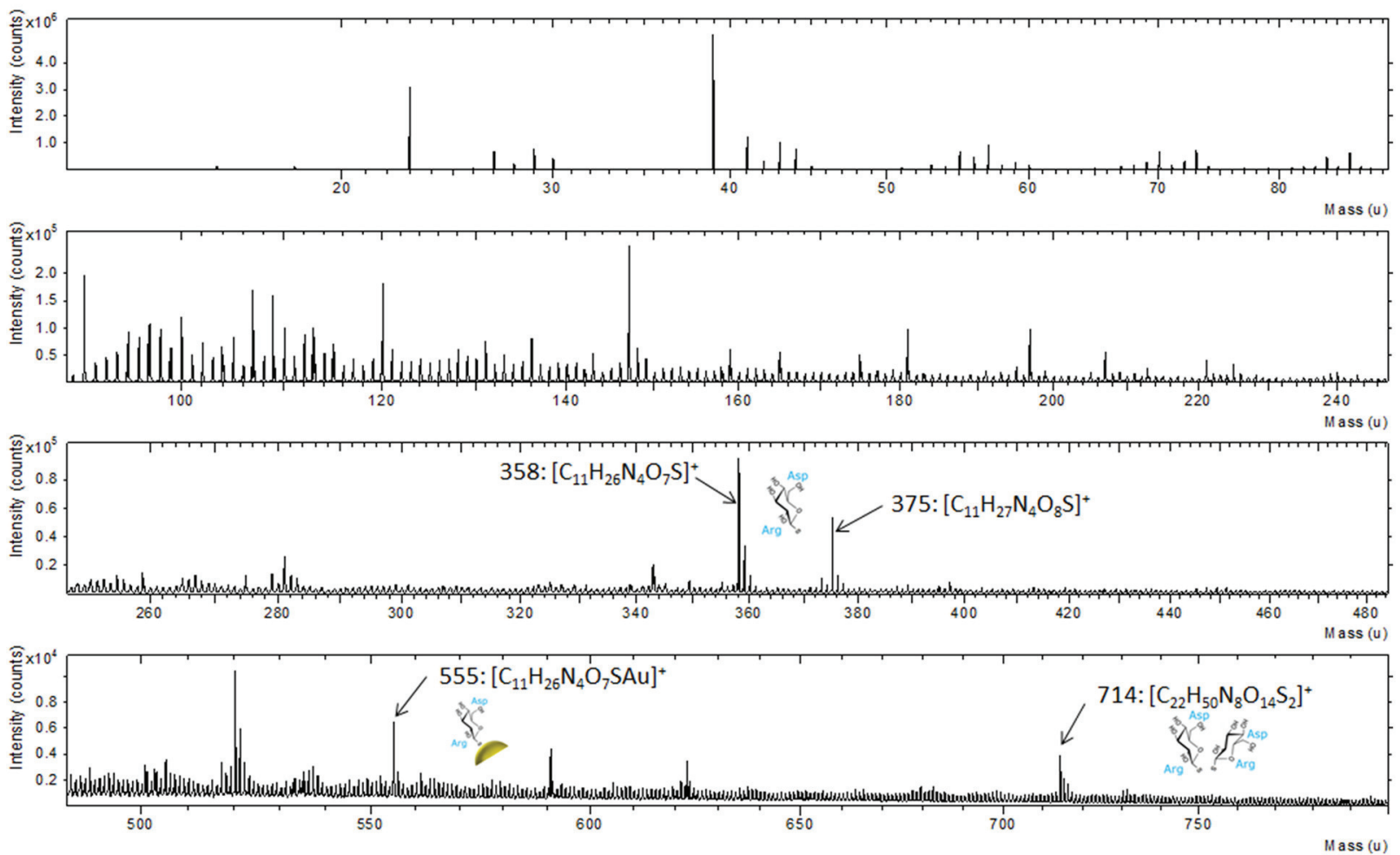

FIGURE 6 | (A) Portions of positive ToF-SIMS spectrum recorded on Au NPs after functionalization with TG thiols and interaction with MBP; (B) Full positive ToF-SIMS spectrum with the high mass peaks related to the MBP-nanoparticles fragments. 

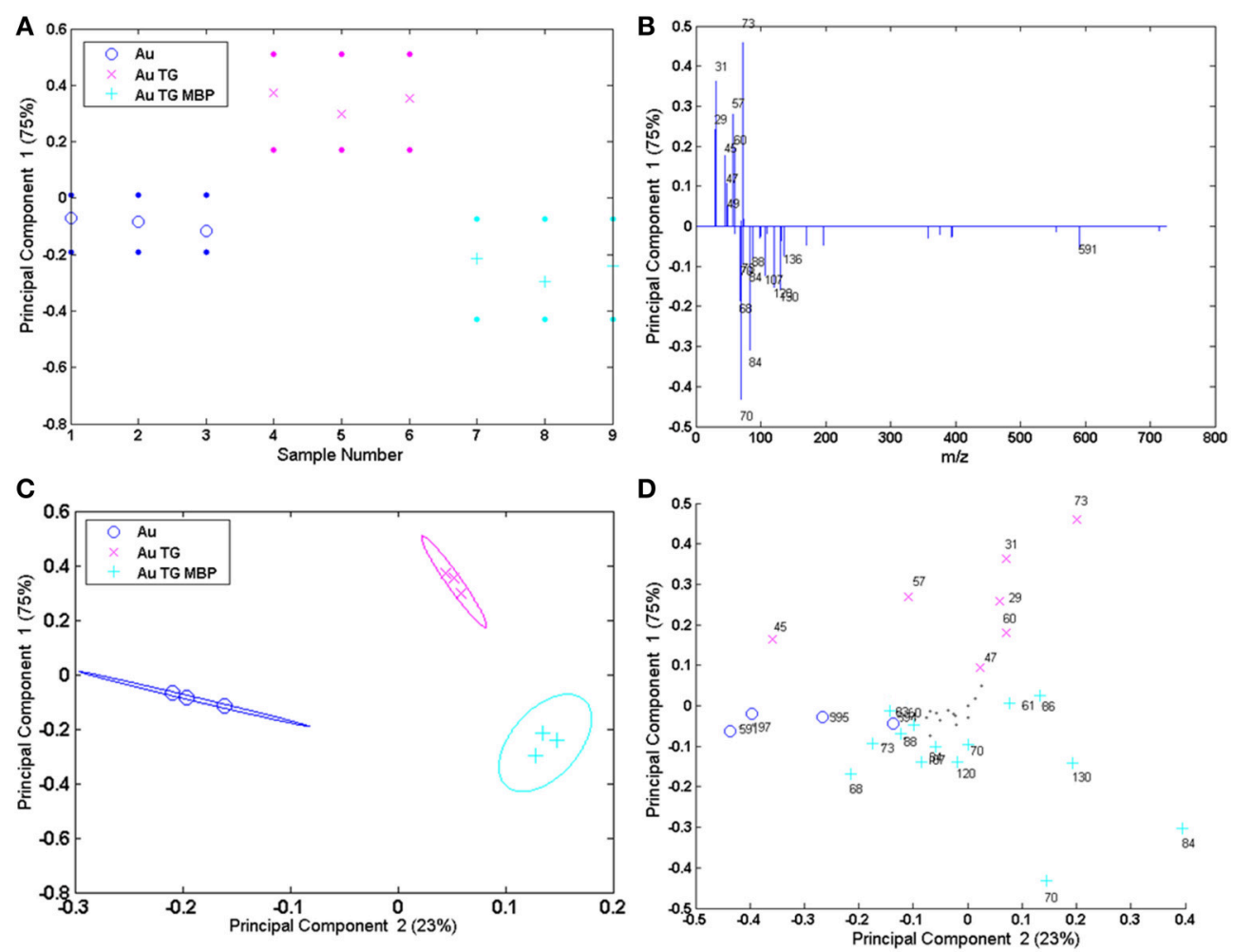

FIGURE 7 | PCA results of the Au flat samples: (A,B) PC1 scores and corresponding loading plots; (C,D) PC1 vs. PC2 scores and corresponding loading plots.

$714 \mathrm{u}$ the fragment $\mathrm{C}_{22} \mathrm{H}_{50} \mathrm{~N}_{8} \mathrm{O}_{14} \mathrm{~S}_{2}$ that can be attributed to the respective dimer is also observed. These assignments take into account the geometry of interaction between the sugar and the protein. In fact, the binding pocket of the MBP exposes some specific amino acidic residues that bind the sugar, as described in literature (Herman et al., 2006; Denis Bucher et al., 2011).

\section{Principal Component Analysis of ToF-SIMS Data}

As reported above, some of the ToF-SIMS data in the case of AuNPs could give ambiguous information due to the presence of citrate stabilizing anions and the complexity of the spectra.

One possible solution for extracting useful information from these complex datasets is the application of multivariate analysis (MVA) techniques and in particular the Principal Component Analysis (PCA) (Jackson, 1991; Anderson, 2013). PCA is a useful tool that can help in determining from which peaks the variability between samples arises after the surface modifications and it has been successfully applied in several studies involving ToF-SIMS analysis (Lockyer and Vickerman, 2005; Graham et al., 2006; Tyler et al., 2007; Kim et al., 2008; Yuta Yokoyama et al., 2015). In this paper PCA was carried out using the peak list reported in Table SI. In particular, 9 peaks ascribed to the TG fragmentation, 21 peaks corresponding to the amino acids fragments and 4 peaks related to the gold substrate were selected. Moreover, the four peaks ascribed to the fragments related to the interaction between the protein-binding pocket and the sugar molecules were also included in the peak list (Table SI). The PCA procedure was applied both to the spectra recorded on flat $\mathrm{Au}$ film and on $\mathrm{Au}$ NPS. However, it should be underlined that since some of the peaks ascribed to the TG can be due to the citrate fragmentation, a caution was necessary when analysing the data related to the AuNPs. Figure 7 shows the scores and the loadings plots for the first and the second principal component (PC1 and PC2) related to the flat gold sample. PCs 1 and 2 capture, respectively, 75 and $23 \%$ of the variance in the data set and are able to group the three positive ion spectra according to their different functionalization.

PC 1 differentiates the flat gold substrate and the system reacted with TG and MBP (negative scores and loadings) from the gold functionalized with the sugar (positive scores and loadings). In fact, negative loadings refer to peaks related to the amino acidic residues of the protein and gold clusters, while positive loadings refer to peaks containing only $\mathrm{H}, \mathrm{C}$, and $\mathrm{O}$, thus related to the TG fragmentation. Considering the $\mathrm{PC} 1$ against PC2 further information can be obtained. In fact, PC2 allows separation of the bare gold substrate (PC2 negatively loaded scores and loadings) from the functionalized one (PC2 positively loaded scores and loadings).

The results of the PCA analysis of the AuNPs are reported in Figure 8. The scores and the loadings plots for PC1 and PC2 capture 74 and $17 \%$ of the variance in the data set, respectively, and are able to group the three positive ion spectra according to their different functionalization. In particular, PC1 differentiates the AuNPs reacted with TG and MBP (positively 

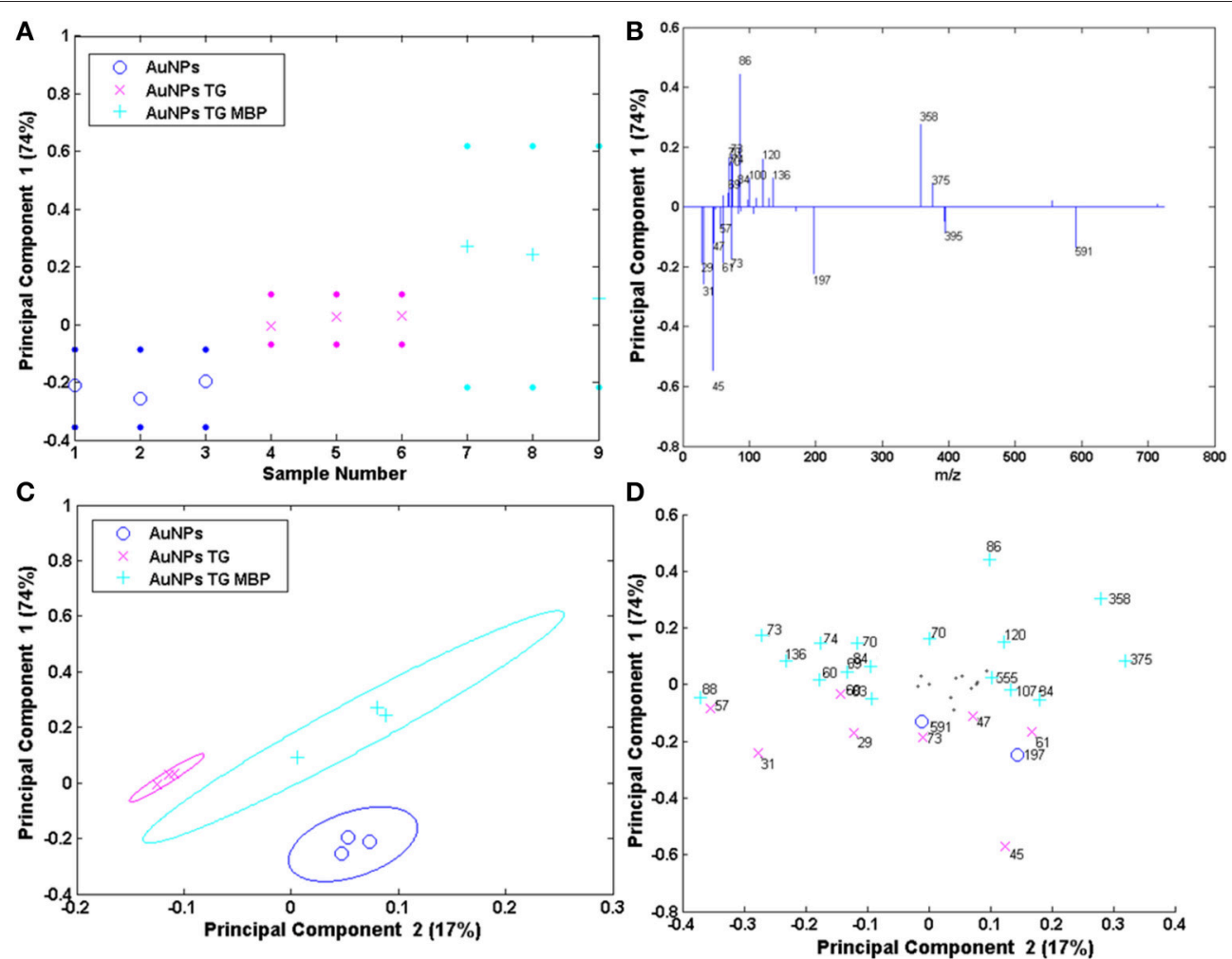

FIGURE 8 | PCA results of the Au NPs samples: (A,B) PC1 scores and corresponding loading plots; (C,D) PC1 vs. PC2 scores and corresponding loading plots.

loaded scores and loadings) from the pristine AuNPs and the ones functionalized with the sugar (scores and loadings negatively loaded). In fact, the peaks with positive loading values are related to the amino acidic residues of the protein and to the peaks related to the interaction between the TG and the MBP binding pocket, while negative loading values refer to peaks containing only $\mathrm{H}, \mathrm{C}, \mathrm{O}$, and $\mathrm{Au}$ corresponding to the TG fragmentation and gold clusters. As reported above, in the case of AuNPs both TG and citrate could desorb from the surface with very similar fragmentation patterns. This could explain why these two systems lay in the portion of the plot loaded with the same polarity. However, considering PC1 against PC2 plots, it is possible to discriminate which peaks are more likely due to the citrate stabilizing agent with respect to those related to TG fragments. In fact, peaks 45, 47 and $61 \mathrm{u}$ are negatively loaded in PC2 projection and are consequently more representative of the citrate stabilized AuNPs. Moreover, the peaks 358 and $375 \mathrm{u}$, related to the complex between the TG and the binding pocket of the protein, are detected in the loadings plots both for PC1 and PC2 as representative peaks of the system AuNPs-TG-MBP, thus confirming the results reported above.

The results obtained in this work indicate that the potential use of TG modified gold nanoparticles as biosensor platform for the detection of MBP could offer advantages due to their large surface area and functionalization flexibility. However, it should be underlined that each functionalization step requires carefully control to assess reproducibility and avoid variation in the MBP structure and specificity. Our results indicate that the TG is interacting with the MBP binding pocket, thus likely preserving the MBP structure and efficiency. In fact, it is known that not all the citrate is displaced during the gold nanoparticles functionalization with thiols (Park and Shumaker-Parry, 2014), leaving a proportion of the surface free to interact with other biomolecules and maybe lowering the sensing efficiency. However, if a careful optimization of the functionalization procedure is carried out more than $60 \%$ of the $\mathrm{Au}$ available sites could be occupied by thiols providing a good platform for biomolecule attachment (Park and Shumaker-Parry, 2015).

\section{CONCLUSIONS}

In this paper we have reported the surface analysis of gold substrates (both as film and nanoparticles) after functionalization with 1-B-D-thio-glucose (TG) and subsequently after interaction with maltose binding protein (MBP) solution. In particular XPS and ToF-SIMS analysis were carried out after each reaction step to assess chemical changes and to identify possible sources of contamination. The data show that the process of functionalization works quite well in the case of the Au flat surface with the possible formation of an ordered TG layer with which the MBP can interact. On the other hand, in the case of $\mathrm{Au}$ nanoparticles, a lower density of TG functionalities was observed, resulting in a lower interaction with MBP molecules. 
However, from the ToF-SIMS data it was possible to determine that the reaction of TG with MBP occurred with specific amino acid residues present in the binding pocket of the protein.

The method presented here illustrates a valid approach for surface analyses of functionalized nanoparticles and the results obtained underline the possibility of using the developed system in biodetection field.

More in general, the present work shows the importance of careful assessment of the surface chemistry of nanomaterials especially when used in complex environments such as biological media.

\section{AUTHOR CONTRIBUTIONS}

Single authors contributed to the present papers as follows: VS carried out part of the functionalization experiments, performed all XPS and ToF-SIMS analysis and data treatment and wrote the paper; MP conceived and performed the functionalization experiments; RL did the gold nanoparticles synthesis and

\section{REFERENCES}

Ambrogio, M. W., Frasconi, M., Yilmaz, M. D., and Chen, X. (2013). New methods for improved characterization of silica nanoparticle-based drug delivery systems. Langmuir 29, 15386-15393. doi: 10.1021/la402493q

Anderson, A. (2013). "Multivariate analysis of SIMS spectra," in ToF-SIMS: Materials Analysis by Mass Spectrometry, eds J. C. Vickerman, D. Briggs (Manchester: Surface Spectra IM Publication), 449-484.

Baer, D. R., Gaspar, D. J., Nachimuthu, P., Techane, S. D., and Castner, D. G. (2010). Application of surface chemical analysis tools for characterization of nanoparticles. Anal. Bioanal. Chem. 396, 983-1002. doi: 10.1007/s00216-0093360-1

Biebuyck, H. A., Colin, D., Bain, C. D., and Whitesides, G. M. (1994). Comparison of organic monolayers on polycrystalline gold spontaneously assembled from solutions containing Dialkyl Disulfides or Alkanethiols. Langmuir 10, 1825-1831. doi: 10.1021/la00018a034

Brigger, I., Dubernet, C., and Couvreur, P. (2002). Nanoparticles in cancer therapy and diagnosis, Adv. Drug Deliv. Rev. 54, 631-651. doi: 10.1016/S0169409X(02)00044-3

Burda, C., Chen, X. B., Narayanan, R., and El-Sayed, M. A. (2005). Chemistry and properties of nanocrystals of different shapes. Chem. Rev. 105, 1025-1102. doi: $10.1021 / \mathrm{cr} 030063 \mathrm{a}$

Camillone, N. III, Chidsey, C. E. D., Liu, G.-Y., Putvinski, T. M., and Scoles, G. (1991). Surface structure and thermal motion of n-alkane thiols self-assembled on $\mathrm{Au}(111)$ studied by low energy helium diffraction. J. Chem. Phys. 94, 8493-8498. doi: 10.1063/1.460082

Chen, H. J., Kou, X. S., Yang, Z., Ni, W. H., and Wang, J. F. (2008). Shape- and size-dependent refractive index sensitivity of gold nanoparticles. Langmuir 24, 5233-5237. doi: 10.1021/la800305j

Csaki, A., Maubach, G., Born, D., Reichert, J., and Fritzsche, W. (2002). DNAbased molecular nanotechnology. Single Mol. 3, 275-280. doi: 10.1002/14385171(200211)3:5/6<275::AID-SIMO275>3.0.CO;2-0

Curry, T., Kopelman, R., Shilo, M., and Popovtzer, R. (2014). Multifunctional theranostic gold nanoparticles for targeted CT imaging and photothermal therapy. Contrast Media Mol. Imaging 9, 53-61. doi: 10.1002/cmmi.1563

Cyganik, P., Buck, M., Azzam, W., and Woll, C. (2004). Self-Assembled Monolayers of $\omega$-Biphenylalkanethiols on $\mathrm{Au}(111)$ : influence of spacer chain on molecular packing. J. Phys. Chem. B 108, 4989-4996. doi: 10.1021/jp037307f

Daniel, M. C., and Astruc, D. (2004). Gold nanoparticles: assembly, supramolecular chemistry, quantum size-related properties, and applications toward biology, catalysis, and nanotechnology. Chem. Rev. 104, 293-346. doi: $10.1021 / \mathrm{cr} 030698+$ characterization; FR supervised the work and revised the paper; GC wrote the paper and supervised the surface analysis work.

\section{ACKNOWLEDGMENTS}

This work was carried out within the European Commission, FP7 Project Biosensor nanoarrays for environmental monitoring (BIOMONAR, grant No: Grant Agreement 244405) and within the JRC institutional action Nanobiosciences. The authors would like to acknowledge Dr. D. Graham (NESLAB, University of Washington, USA) for providing the MVA toolbox used for the PCA data analysis. Finally the authors are grateful to Dr. D. Gilliland (JRC-IHCP) for revising the manuscript.

\section{SUPPLEMENTARY MATERIAL}

The Supplementary Material for this article can be found online at: http://journal.frontiersin.org/article/10.3389/fchem. 2016.00008

Davis, M. E., Chen, Z., and Shin, D. M. (2008). Nanoparticle therapeutics: an emerging treatment modality for cancer. Nat. Rev. Drug Dis. 7, 771-782. doi: $10.1038 / \mathrm{nrd} 2614$

De Champdore, M., Staiano, M., Aurilia, V., Stepanenko, O. V., Parracino, A., Rossi, M., et al. (2006). Thermostable proteins as probe for the design of advanced fluorescence biosensors. Rev. Environ. Sci. Biotechnol. 5, 233-242. doi: 10.1007/s11157-006-0009-9

Denis Bucher, D., Grant, B. J., Markwick, P. R., and McCammon, J. A. (2011). Accessing a hidden conformation of the maltose binding protein using accelerated molecular dynamics. PLoS Comput. Biol. 7:e1002034. doi: 10.1371/journal.pcbi.1002034

Dubois, L. H. and Nuzzo, R. G. (1992). Synthesis, Structure, and properties of model organic surfaces. Ann. Rev. Phys. Chem. 43, 437-463. doi: 10.1146/annurev.pc.43.100192.002253

Fonin, A. V., Povarova, O. I., Staiano, M., D’Auria, S., Turoverov, K. K., and Kuznetsova, I. M. (2014). The trehalose/maltose-binding protein as the sensitive element of a glucose biosensor. Opt. Mater. 36, 1676-1679. doi: 10.1016/j.optmat.2014.01.001

Graham, D. J., Wagner, M. S., and Castner, D. G. (2006). Information from complexity: challenges of TOF-SIMS data interpretation. App. Surf. Sci. 252, 6860-6868. doi: 10.1016/j.apsusc.2006.02.149

Grainger, D. W., and Castner, D. G. (2008). Nanobiomaterials and nanoanalysis: opportunities for improving the science to benefit biomedical technologies. Adv. Mat. 20, 867-877. doi: 10.1002/adma.200701760

Herman, P. I., Staiano, M., Marabotti, A., Varriale, A., Scirè A., Tanfani, F., et al. (2006). D-trehalose/D-maltose-binding protein from the hyperthermophilic archaeon Thermococcus litoralis: the binding of trehalose and maltose results in different protein conformational states. Proteins 63, 754-767. doi: $10.1002 /$ prot.20952

Homola, J. (2008). Surface plasmon resonance sensors for detection of chemical and biological species. Chem. Rev. 108, 462-493. doi: 10.1021/cr06 $8107 \mathrm{~d}$

Jackson, J. E. (1991). A User's Guide to Principal Components. New York, NY: Wiley. doi: 10.1002/0471725331

Jain, P. K., Huang, X., El-Sayed, I. H., and El-Sayed, M. A. (2007). Review of some interesting surface plasmon resonance-enhanced properties of noble metal nanoparticles and their applications to biosystems. Plasmonics 2, 107-118. doi: 10.1007/s11468-007-9031-1

Kapust, R. B., and Waugh, D. S. (1999). Escherichia coli maltose-binding protein is uncommonly effective at promoting the solubility of polypeptides to which it is fused. Protein Sci. 8, 1668-1674. doi: 10.1110/ps.8. 8.1668 
Katz, E., Shipway, A. N., and Willner, I. (2003). "Biomaterial-nanoparticle hybrid systems: synthesis, properties, and applications," in NanoparticlesFrom Theory to Applications, ed. G. Schmid (Weinheim: Wiley-VCH), 368-421.

Katz, E., and Willner, I. (2004). Integrated nanoparticle-biomolecule hybrid systems: synthesis, properties, and applications. Angew. Chem. Int. Ed. 43, 6042-6108. doi: 10.1002/anie.200400651

Kim, Y. P., Hong, M.-Y., Shon, K. Y., Chegal, W., Cho, H. M., Moon, D. W., et al. (2008). Protein quantification on dendrimer-activated surfaces by using timeof-flight secondary ion mass spectrometry and principal component regression. Appl. Surface Sci. 255, 1110-1112. doi: 10.1016/j.apsusc.2008.05.044

Kim, Y.-P., Shon, K.-H., Shin, S.-K., and Lee, T. J. (2015). Probing nanoparticles and nanoparticle-conjugated biomolecules using time-of-flight secondary ion mass spectrometry. Mass Spectrom. Rev. 34, 237-247. doi: 10.1002/mas.21437

Lebec, V., Landoulsi, J., Boujday, S., Poleunis, C., Pradier, C.-M., and Delcorte, A. (2013). Probing the orientation of $\beta$-lactoglobulin on gold surfaces modified by Alkyl Thiol self-assembled monolayers. J. Phys. Chem. C 117, 11569-11577. doi: $10.1021 / \mathrm{jp} 311964 \mathrm{~g}$

Lee, K. S., and El-Sayed, M. A. (2006). Gold and silver nanoparticles in sensing and imaging: sensitivity of plasmon response to size, shape, and metal composition. J. Phys. Chem. B 110, 19220-19225. doi: 10.1021/jp062536y

Lockyer, N. P. and Vickerman, J. C. (2005). Progress in cellular analysis using ToF-SIMS. Appl. Surf. Sci. 231-232, 377-384. doi: 10.1016/j.apsusc.2004.03.103

Lu, H. B., Campbell, C. T., and Castner, D. G. (2000). Attachment of functionalized Poly(ethylene glycol) films to gold surfaces. Langmuir 16, 1611-1618. doi: $10.1021 / \mathrm{la} 990221 \mathrm{~m}$

Maina, C. V., Riggs, P. D., Grandea, A. G. III., Slatko, B. E., Moran, L. S., Tagliamonte, J. A., et al. (1988). An Escherichia coli vector to express and purify foreign proteins by fusion to and separation from maltose-binding protein. Gene 74, 365-373. doi: 10.1016/0378-1119(88)90170-9

Medintz, I. L., and Deschamps, J. R. (2006). Maltose-binding protein: a versatile platform for prototyping biosensing. Curr. Opin. Biotechnol. 17, 17-27. doi: 10.1016/j.copbio.2006.01.002

Neoh, K. G., Li, M., and Kang, E.-T. (2015). "Characterization of nanomaterials/nanoparticles," in Nanotechnology in Endodontics, ed A. Kishen (Springer International Publishing), 23-44.

Niemeyer, C. M. (2001). DNA-directed functionalization of colloidal gold with proteins. Angew. Chem. 113, 4254-4287. doi: 10.1002/15213757(20011119)113:22<4254::AID-ANGE4254>3.0.CO;2-D

Niemeyer, C. M. (2003). Oligofunctional DNA-Gold nanoparticle conjugates. Angew. Chem. Int. Ed. Engl. 42, 5796-5800. doi: 10.1002/anie.200352744

Njoki, P. N., Lim, I. I. S., Mott, D., Park, H. Y., Khan, B., Mishra, S., et al. (2007). Size correlation of optical and spectroscopic properties for gold nanoparticles. J. Phys. Chem. C 111, 14664-14669. doi: 10.1021/jp074902z

Ojea-Jiménez, I., and Puntes, V. (2009). Instability of cationic gold nanoparticle bioconjugates: the role of citrate ions. J. Am. Chem. Soc. 131, 13320-13327. doi: $10.1021 /$ ja902894s

Okpalugo, T. I. T., Papakonstantinou, P., Murphy, H., McLaughlin, J., and Brown, N. M. D. (2005). High-resolution XPS characterization of chemical functionalized MWCNTs and SWCNTs. Carbon 43, 153-161. doi: 10.1016/j.carbon.2004.08.033

Oliver, N. S., Toumazou, C., Cass, A. E., and Johnston, D. G. (2009). Glucose sensors: a review of current and emerging technology. Diabet. Med. 26, 197-210. doi: 10.1111/j.1464-5491.2008.02642.x

Parak, W. J., Gerion, D., Pellegrino, T., Zanchet, D., Micheel, C., Williams, S. C., et al. (2003). Biological applications of colloidal nanocrystals. Nanotechnology 14, R15-R27. doi: 10.1088/0957-4484/14/7/201

Park, J.-W., and Shumaker-Parry, J.-S. (2014). Structural study of citrate layers on gold nanoparticles: role of intermolecular interactions in stabilizing nanoparticles. J. Am. Chem. Soc. 136, 1907-1921. doi: 10.1021/ja4097384

Park, J.-W., and Shumaker-Parry, J.-S. (2015). Strong resistance of citrate anions on metal nanoparticles to desorption under thiol functionalization. ACSNano 9, 1665-1682. doi: $10.1021 / \mathrm{nn} 506379 \mathrm{~m}$

Pinnick, V., Rajagopalachary, S., Verkhoturov, S. V., Kaledin, L., and Schweikert, E. A. (2008). Characterization of individual nano-objects by secondary ion mass spectrometry. Anal. Chem. 80, 9052-9057. doi: 10.1021/ac8014615

Ray, S., and Shard, A. G. (2011). Quantitative analysis of adsorbed proteins by X-ray photoelectron spectroscopy. Anal. Chem. 83, 8659-8666. doi: $10.1021 / \mathrm{ac} 202110 \mathrm{x}$
Schreiber, F. (2000). Structure and growth of self-assembling monolayers. Progr. Surf. Sci. 65, 151-256. doi: 10.1016/S0079-6816(00)00024-1

Shard, A. G. (2012). A straightforward method for interpreting XPS data from Core-Shell nanoparticles. J. Phys. Chem. C 116, 16806-16813. doi: $10.1021 /$ jp305267d

Spampinato, V., Giordani, S., and Ceccone, G. (2015). Surface analysis of functionalized carbon nano-onions. Biointerphases 10, 019006 . doi: $10.1116 / 1.4907726$

Sperling, R. A., Rivera Gil, P., Zhang, F., Zanella, M., and Parak, W. J. (2008). Biological applications of gold nanoparticles. Chem. Soc. Rev. 37, 1896-1908. doi: 10.1039/b712170a

Techane, S. D., Gamble, L. J., and Castner, D. G. (2011). X-ray photoelectron spectroscopy characterization of gold nanoparticles functionalized with amineterminated alkanethiols. Biointerphases 6, 98-103. doi: 10.1116/1.3622481

Turkevich, J., Stevenson, P. C., and Hillier, J. (1951). A study of the nucleation and growth processes in the synthesis of colloidal gold. Discuss. Faraday Soc. 11, 55-75. doi: 10.1039/df9511100055

Tyler, B. J., Rayal, G., and Castner, D. G. (2007). Multivariate analysis strategies for processing ToF-SIMS images of biomaterials. Biomaterials 28, 2412-2423. doi: 10.1016/j.biomaterials.2007.02.002

Ulman, A. (1996). Formation and structure of self-assembled monolayers, Chem. Rev. 96, 1533-1554. doi: 10.1021/cr9502357

Vanea, E., and Simon, V. (2011). XPS study of protein adsorption onto nanocrystalline aluminosilicate microparticles. Appl. Surf. Sci. 257, 2346-2352. doi: 10.1016/j.apsusc.2010.09.101

Vericat, C., Vela, M. G., Benitez, G. A., Martin Gago, J. M., Torrelles, X., and Salvarezza, R. C. (2006). Surface characterization of sulfur and alkanethiolselfassembled monolayers on $\mathrm{Au}(111)$. J. Phys. Condens. Matter. 18, R867-R900. doi: 10.1088/0953-8984/18/48/R01

Wagner, M. S., and Castner, D. G. (2001). Characterization of adsorbed protein films by time-of-flight secondary ion mass spectrometry with principal component analysis. Langmuir 17, 4649-4660. doi: 10.1021/la001209t

Wang, A. Z., Langer, R., and Farokhzad, O. C. (2012). Nanoparticle delivery of cancer drugs. Ann. Rev. Med. 63, 185-198. doi: 10.1146/annurev-med-040210162544

Wang, H., Castner, D. G., Ratner, B. D., and Shaoyi, J. S. (2004). Probing the orientation of surface-immobilized immunoglobulin $g$ by time-offlight secondary ion mass spectrometry. Langmuir 20, 1877-1887. doi: $10.1021 / \mathrm{la} 035376 \mathrm{f}$

Xavier, K. B., Martins, L. O., Peis, R., Kossmann, M., Boos, W., and Santos, H. (1996). High-affinity maltose/trehalose transport system in the hyperthermophilic archaeon Thermococcus litoralis. J. Bacteriol. 178, 4773-4777

Yang, D.-Q., Gillet, J.-N., Meunier, M., and Sacher, E. (2005). Room temperature oxidation kinetics of Si nanoparticles in air, determined by X-ray photoelectron spectroscopy. J. Appl. Phys. 97, 024303-024310. doi: 10.1063/1.1835566

Yuta Yokoyama, Y., Kawashima, T., Ohkawa, M., Iwaid, H., and Aoyagi, S. (2015). Extraction of hidden information of ToF-SIMS data using different multivariate analyses. Surf. Interface Anal. 47, 439-446. doi: 10.1002/sia.5731

Zhang, F., Wang, P., Koberstein, J., Khalid, S., and Chan, S.-W. (2004). Cerium oxidation state in ceria nanoparticles studied with X-ray photoelectron spectroscopy and absorption near edge spectroscopy. Surf. Sci. 563, 74-82. doi: 10.1016/j.susc.2004.05.138

Zorn, G., Dave, S. R., Gao, X., and Castner, D. G. (2011). Method for determining the elemental composition and distribution in semiconductor core-shell quantum dots. Anal. Chem. 83, 866-873. doi: 10.1021/ac102516n

Conflict of Interest Statement: The authors declare that the research was conducted in the absence of any commercial or financial relationships that could be construed as a potential conflict of interest.

Copyright ( 2016 Spampinato, Parracino, La Spina, Rossi and Ceccone. This is an open-access article distributed under the terms of the Creative Commons Attribution License (CC BY). The use, distribution or reproduction in other forums is permitted, provided the original author(s) or licensor are credited and that the original publication in this journal is cited, in accordance with accepted academic practice. No use, distribution or reproduction is permitted which does not comply with these terms. 